\title{
Atrial Myxoma with a Dual Coronary Artery Supply
}

\author{
Massar Omar ${ }^{1}$, Jesper Eske Sindby ${ }^{2}$, Asta Blaskauskaite ${ }^{3}$, Tomas Zaremba ${ }^{1}$, \\ Svend Eggert Jensen ${ }^{1,4}$
}

\author{
${ }^{1}$ Department of Cardiology, Aalborg University Hospital, Aalborg, Denmark \\ ${ }^{2}$ Department of Thoracic Surgery, Aalborg University Hospital, Aalborg, Denmark \\ ${ }^{3}$ Department of Cardiology, Hjorring Hospital, Hjorring, Denmark \\ ${ }^{4}$ Department of Clinical Medicine, Aalborg University, Aalborg, Denmark \\ Email: Massar_omar@hotmail.com, jeess@rn.dk, asbl@rn.dk,tz@rn.dk,svend.eggert.jensen@rn.dk
}

How to cite this paper: Omar, M., Sindby, J.E., Blaskauskaite, A., Zaremba, T. and Jensen, S.E. (2017) Atrial Myxoma with a Dual Coronary Artery Supply. International Journal of Clinical Medicine, 8, 368-374. https://doi.org/10.4236/ijcm.2017.86034

Received: March 28, 2017

Accepted: June 19, 2017

Published: June 22, 2017

Copyright (c) 2017 by authors and Scientific Research Publishing Inc. This work is licensed under the Creative Commons Attribution International License (CC BY 4.0).

http://creativecommons.org/licenses/by/4.0/

\section{c) (i) Open Access}

\begin{abstract}
Primary cardiac tumours are rare, with myxoma being the most common benign heart tumour. The prevalence of coronary disease or neovascular in patients with atrial myxomas is high, yet angiography is not routinely performed. Echocardiography is preferred for evaluation of myxoma, where coronary angiography clarifies the vascular supply of the tumour and may alter the surgical planning. We here report an interesting and rare case of a left atrial myxoma hyper vascularised by two anomalous arteries, from right coronary artery and circumflex artery demonstrated by preoperative coronary angiography. The mass was successfully excised and the diagnosis of cardiac myxoma was confirmed via histopathology. A review of the value of coronary angiography in detecting myxoma neovascularization is provided. Offering additional valuable information, coronary angiography can alter the surgical approach and may therefore be considered prior to myxoma resection.
\end{abstract}

\section{Keywords}

Atrial Myxoma, Cardiac Tumour, Coronary Angiography, Stroke, Echocardiography, Embolism, Coronary Vascularisation, Case Report

\section{Introduction}

Atrial Myxoma tumours are rare, but are nonetheless the most common among primary heart tumours. Approximately $85 \%$ of the myxomas are located in the left atrium [1], where the tumour is typically pedunculated attached to the left atrial septum in the region of fossa ovalis. The mean age of the patients with myxoma is 56 years and $70 \%$ are female [2]. Symptoms are weak and nonspecif- 
ic, which makes early diagnosis a challenge. Symptoms could be presented as dyspnea, palpitations and atrial embolism [3] [4] [5].

Over the past three decades, diagnosis of cardiac myxomas through echocardiography has been the favoured procedure and major diagnostic tool. Other imaging techniques such as magnetic resonance imaging (MRI), scintigraphy and computed tomography (CT) imaging have also proven their usefulness in diagnosis. As echocardiography is a routine procedure in the detection of myxomas, coronary angiography is only performed under special circumstances.

The main arguments against performing coronary angiography routinely in all myxoma cases include the procedure-related complications and risk of sudden death [6]. At the present time, the indications of coronary angiography to rule out coronary artery disease before myxoma excision are primarily based on the patient's age and gender or the presence of angina. In previous observational studies, coronary angiography was performed in $27 \%$ - $85 \%$ of cases before surgery, and the main reason was to rule out subclinical coronary artery disease [6] [7]. However, beyond coronary angiography's value in ruling out coronary artery disease before surgery, coronary angiography is essential in detecting the neovessels of the tumour. Coronary angiography visualises feeding vessels, which has several clinical and therapeutic implications. A nonvascularized myxoma with blood leak into the atria can create a steal phenomenon and subsequent myocardial ischemia. The steal phenomenon can be due to the spurting of blood from the myxoma surface. Umeda et al. reported a right atrial myxoma, where bleeding from the tumour surface was noted during surgery [8].

This report presents a 56-year-old female diagnosed by an atrial myxoma through echocardiography. The patient had a coronary angiography to exclude treatable coronary artery disease and evaluate tumour neovascular. This revealed a rare condition with a left atrial myxoma vascularised with two anomalous arteries arriving from right coronary artery (RCA) and circumflex coronary artery (CX). The findings lead us to believe that all patients with cardiac myxomas should have coronary angiography as routine workup.

\section{Case Description}

\section{This Case Report Is Created with the Patient's Consent}

A 56-year-old female, previously without neurovascular disease, was admitted to the hospital with a cerebral ischemic stroke documented with MRI. The symptoms were blurred speech, dizziness and decreased force in the right hand, all with a duration of less than one minute. Subsequently, the patient showed a complete recovery and free of symptoms. The physical examination was normal, with normal auscultation of heart and lungs. Previously, the patient had undergone a full pulmonary examination due to coughing, and all tests had shown normal results.

More recently, cerebral MRI scanning demonstrated 2 - 3 cortical located diffusion weighted imaging (DWI)-positive lesions frontal on the left side.

Routinely, the patient underwent cardiac examination to determine the cause 
of the vascular event, ECG was found to be normal.

Transthoracic echocardiography revealed a tumour originating from the interatrial septum fossa ovalis in the left atrium (Figure 1). To determine the size and shape a CT-scan of the heart was conducted; the tumour measured $51 \times 49 \times$ $37 \mathrm{~mm}$ (Figure 2). Coronary angiography revealed abnormal arterial supply from RCA and CX to the tumour (Figure 3).

The patient underwent surgical treatment with a median sternotomy, and during surgery a tumour the size of a golf ball was removed (Figure 4). Histologically, it proved to be myxoma (Figure 5). The patient had an uneventful postoperative course and was discharged 5 days after the surgery in well-being. Echocardiography performed four months after the surgery showed no evidence of myxoma recurrence and the patient was asymptomatic, without adverse events.
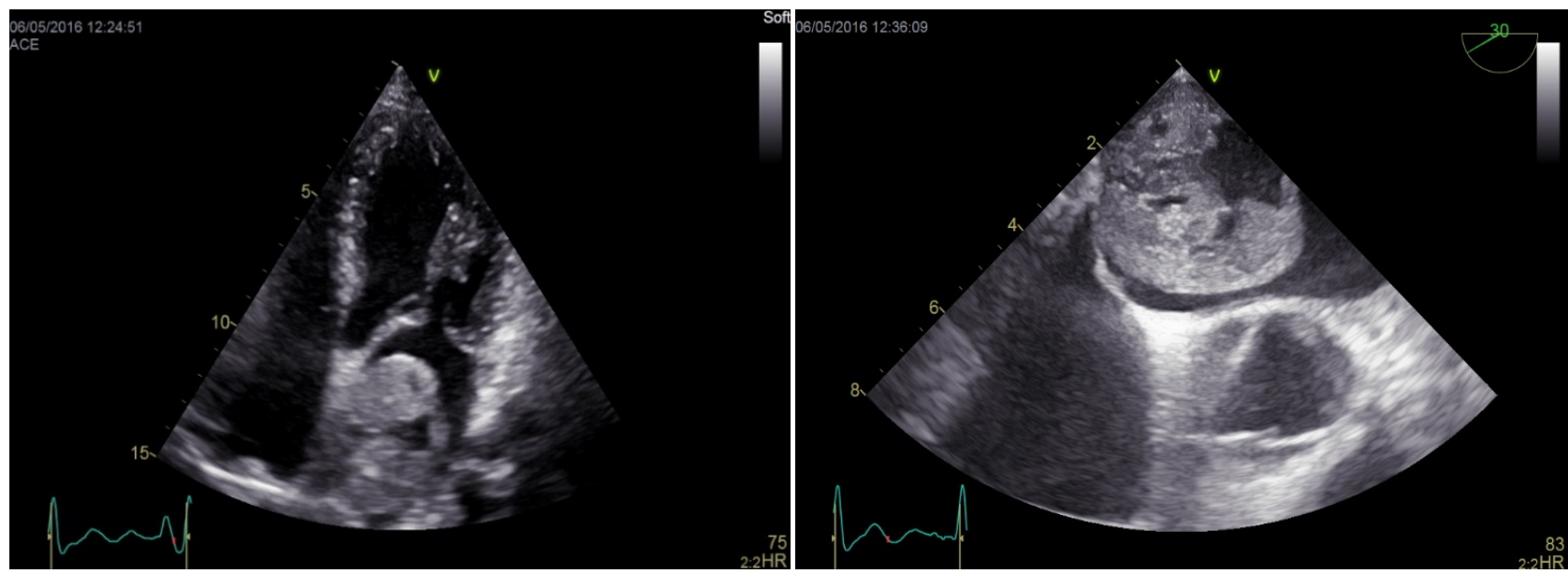

Figure 1. Transthoracic echocardiography showing a huge left atrialmyxoma. Left: two chambers view with the myxoma in left atrium, attached to the upper area of interatrial septum. Right: transoesophageal echocardiography with myxoma located in left atrium.
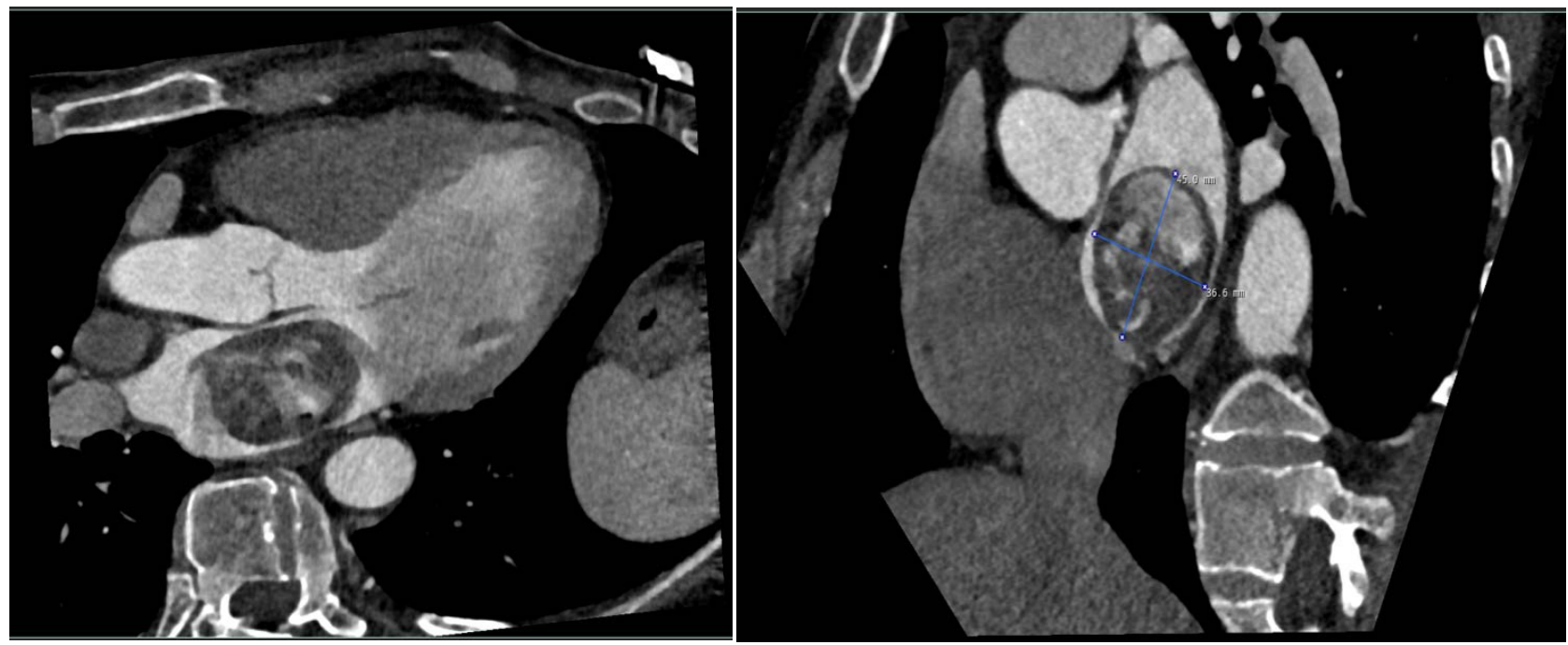

Figure 2. Computed tomography of the heart with intravenous contrast demonstrating a large filling defect in the left atrium. The myxoma measured $51 \times 49 \times 37 \mathrm{~mm}$. 

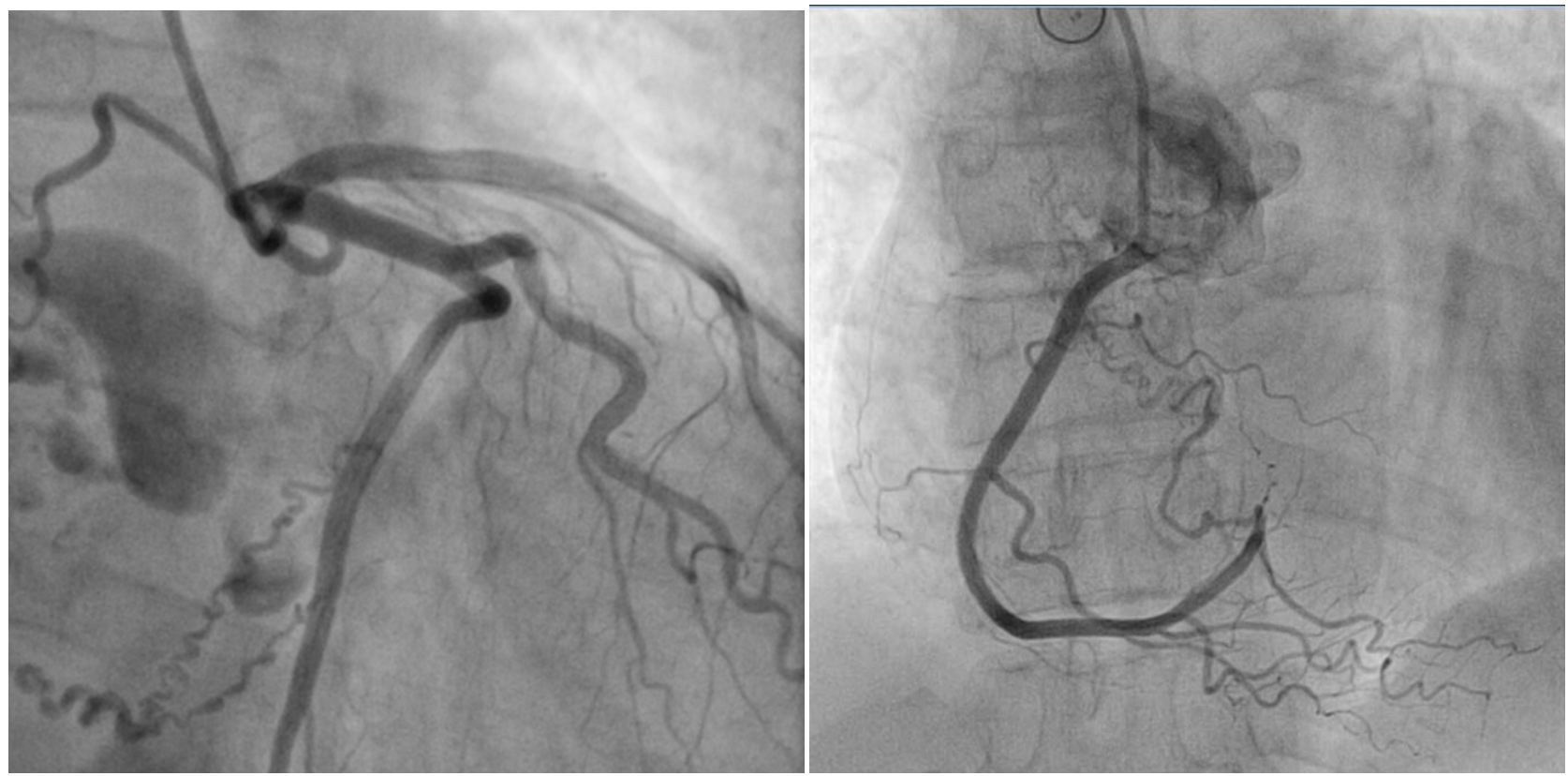

Figure 3. Anomalous vessel supply to the myxoma. Angiogram of the circumflex (left) and right coronary (right), demonstrating supply to the mass.
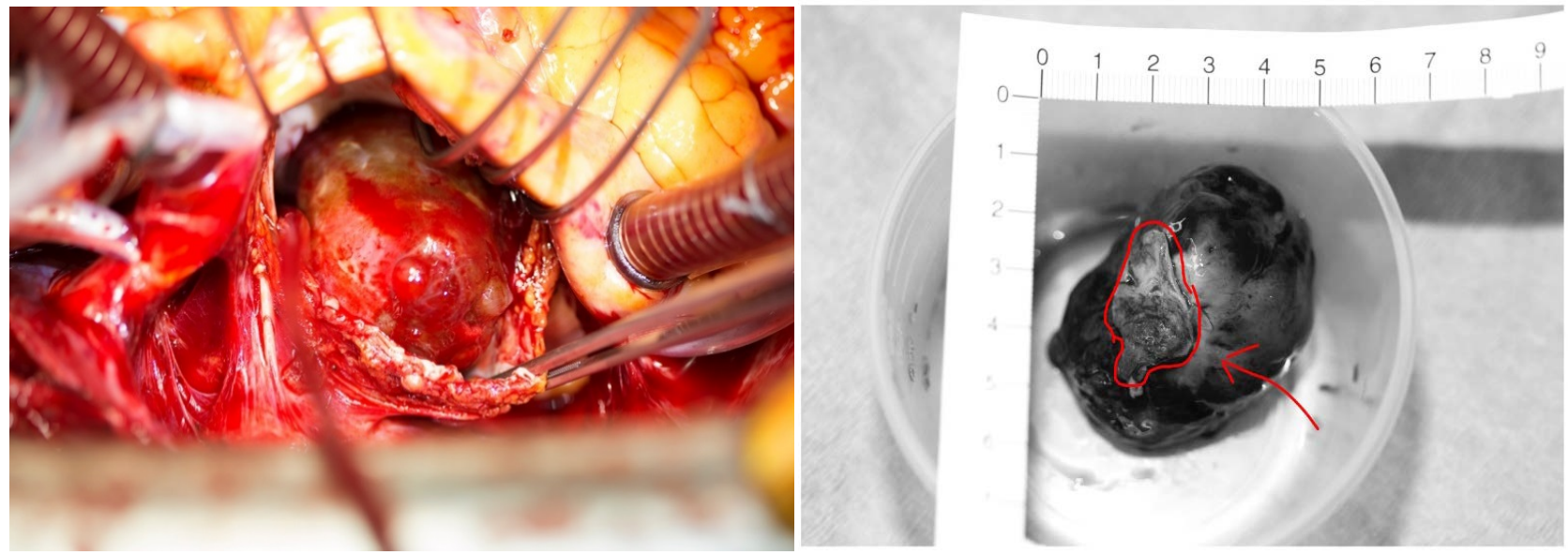

Figure 4. Photograph showing the resected left atrial mass. The red line on the right picture shows the attachment of the myxoma.

\section{Discussion}

Myxomas are the most frequent benign form of heart tumour. The majority of the myxomas (85\%), are located in the left atrium [3] [9]. Although the myxomas are histologically benign, they may nonetheless be lethal because of their position. Mattle et al. [10] report that myxomas initially manifest with features of embolic stroke in approximately a third of patients, as in our patient. Other patients can develop cardiac failure due to obstructed filling causing dyspnea or syncope, as reported by Simsek et al. [11]. Some myxomas are asymptomatic and are discovered as an incidental finding.

Detecting myxoma through echocardiography is the first choice procedure; however, coronary angiography and computed tomography can be useful in diagnosing and evaluating the supply of atrial myxomas [9] [12]. The origin of the 


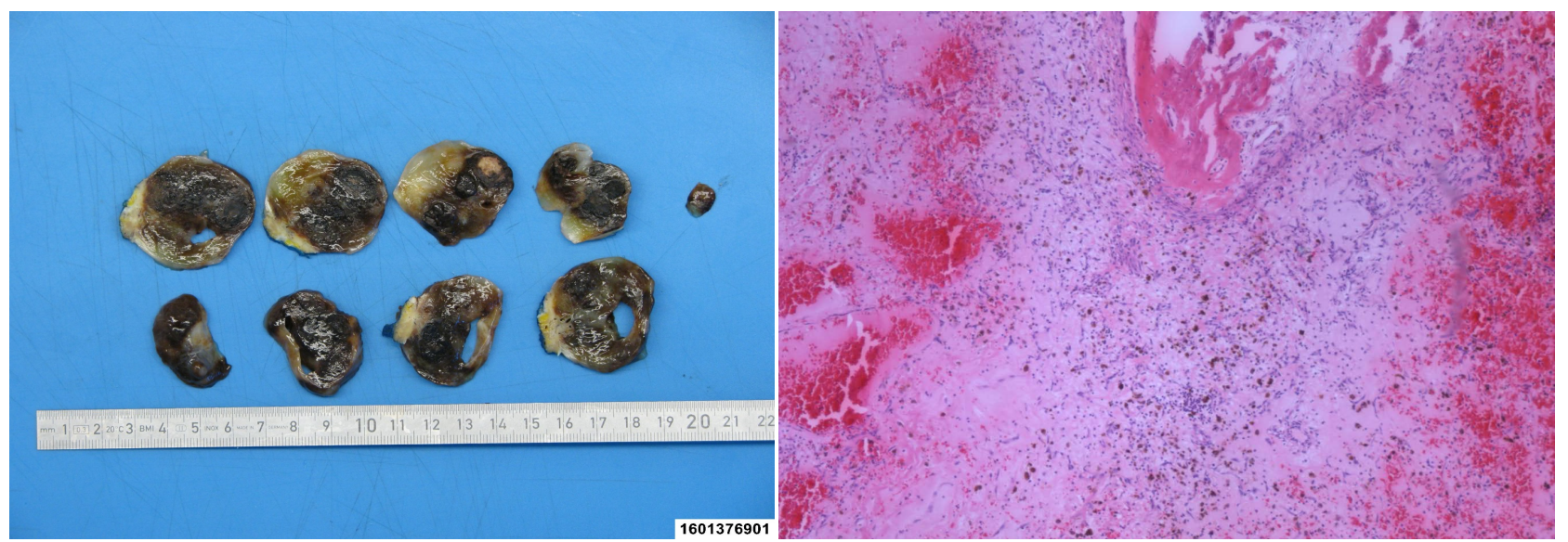

Figure 5. Left: photograph shows the macroscopic resected left atrial mass, sliced before histology. Right: the classic structure of cardiac myxoma is shown. There are areas with larger vessels containing blood (left), fresh bleeding (right) and calcification with suggested osseous metaplasia (top centre). ( $\mathrm{H} \& \mathrm{E}$, orig. $\times 10)$.

vessels supplying the tumour is most commonly CX followed by the RCA [6], while a limited number of studies have demonstrated the rare condition with coexisting coronary artery supply as seen in our case [12] [13] [14] [15] [16].

There is considerable variation in the way the growth rate of myxomas is reported. In one review, an average rate of growth of $0.15 \mathrm{~cm}$ per month in one plan was described [17]. The current case, however, raises the idea of a more rapid growth rate due to dual supply. However, no studies have measured the growth rate on myxoma with dual supply.

Today, surgical resection of myxomas safe, with very low mortality or morbidity rate [8]. A previous case report describes a case of left atrial myxoma mimicking an atrial thrombus on echocardiography, thereby posing diagnostic difficulty [18]. Here, differentiating between these two masses through coronary angiography is of value. Both of which have different therapeutic approaches (surgery in the myxoma and anticoagulation in thrombi). The presence of neovascularisation favours the diagnosis of a cardiac myxoma rather than thrombus, which is most often non-vascularised.

Neovascularisation of atrial myxomas with blood leak into the atria can create a steal phenomenon and subsequent myocardial ischemia. The steal phenomenon is defined as a leak from the coronary artery into the atria, causing blood to spurt from the myxomas surface. A study has reported bleeding from a myxomas surface during surgery [8]. The visualisation of coronary supply to myxoma has changed the surgical approach where identifying the supplying arterial branches was preformed to prevent postoperative steal phenomenon and myocardial ischemia [5] [19]. Surgical excision is the definitive treatment and should not be delayed because of the incidence of embolization; however, as mentioned in our discussion, angiographic visualisation of the feeding vessels has several clinical and therapeutic implications.

\section{Conclusion}

In conclusion, we advocate the use of preoperative coronary angiography in all 
cases of atrial myxomas even in the absence of angina symptoms. Furthermore, the angiographic presence of tumour neovascular should be recognised as it may potentially pose a significant challenge to surgeons.

\section{Disclosure of Interest}

The authors report no conflicts of interest.

\section{References}

[1] Di Vito, A., Mignogna, C. and Donato, G. (2015) The Mysterious Pathways of Cardiac Myxomas: A Review of Histogenesis, Pathogenesis and Pathology. Histopathology, 66, 321-332. https://doi.org/10.1111/his.12531

[2] Erdil, N., Ates, S., Cetin, L., Demirkilic, U., Sener, E. and Tatar, H. (2003). Frequency of Left Atrial Myxoma with Concomitant Coronary Artery Disease. Surgery Today, 33, 328-331. https://doi.org/10.1007/s005950300075

[3] Iyer, P., et al. (2016) A Case of Large Atrial Myxoma Presenting as an Acute Stroke. Journal of Community Hospital Internal Medicine Perspectives, 6, Article ID: 29604. https://doi.org/10.3402/jchimp.v6.29604

[4] Ihsen, Z., et al. (2016) Cerebral Embolism Complicating Left Atrial Myxoma: A Case Report. Pan African Medical Journal, 24, 140. https://doi.org/10.11604/pamj.2016.24.140.9778

[5] Ekinci, E.I. and Donnan, G.A. (2004) Neurological Manifestations of Cardiac Myxoma: A Review of the Literature and Report of Cases. Internal Medicine Journal, 34, 243-249. https://doi.org/10.1111/j.1444-0903.2004.00563.x

[6] Rahmanian, P.B., Castillo, J.G., Sanz, J., et al. (2007) Cardiac Myxoma: Preoperative Diagnosis Using a Multimodal Imaging Approach and Surgical Outcome in a Large Contemporary Series. Interactive Cardio Vascular and Thoracic Surgery, 6, 479-483. https://doi.org/10.1510/icvts.2007.154096

[7] Huang, C.Y., Yu, W.C., Chen, K.C. and Lin, S.J. (2005) Coronary Angiography of Cardiac Myxoma. Clinical Cardiology, 28, 505-509.

https://doi.org/10.1002/clc.4960281104

[8] Umeda, Y., et al. (2009) Right Atrial Myxoma with Tumor Vascularity Originated from the Left and Right Coronary Arteries. International Journal of Cardiology, 131, e137-e139. https://doi.org/10.1016/j.ijcard.2007.07.084

[9] Elbardissi, A.W., et al. (2008) Survival after Resection of Primary Cardiac Tumors: A 48-Year Experience. Circulation, 118, S7-S15. https://doi.org/10.1161/circulationaha.107.783126

[10] Mattle, H.P., Maurer, D., Stuurzenegger, M., Ozdova, C., Baumgartner, R.W. and Schroth, G. (1995) Cardiac Myxomas: A Long Study. Journal of Neurology, 242, 689-694. https://doi.org/10.1007/BF00866921

[11] Simsek, E., Durdu, S., Hodo, B., Yazicioglu, L. and Uysalel, A. (2013) Left Ventricular Myxoma Producing Cardiac Failure. The Heart Surgery Forum, 16, E57-E59. https://doi.org/10.1532/HSF98.20121063

[12] Yazici, M., et al. (2005) Asymptomatic Giant Left Atrial Myxoma Supplied from Right Coronary Artery in a 65-Year-Old Woman. International Journal of Cardiology, 101, 495-496.

[13] Van Clemput, J., Daenen, W. and De Geest, H. (1993) Coronary Angiography in Cardiac Myxomas: Findings in 19 Consecutive Cases and Review of the Literature. Catheterization and Cardiovascular Interventions, 29, 217-220. 
https://doi.org/10.1002/ccd.1810290308

[14] Vasconcelos, M.C. and Macedo, L.F. (2008) Multicavitated Left Atrial Myxoma with Dual Coronary Supply. Arquivos Brasileiros de Cardiologia, 90, e32.

[15] Omar, H.R. (2015) The Value of Coronary Angiography in the Work-Up of Atrial Myxomas. Herz, 40, 442-446. https://doi.org/10.1007/s00059-013-3930-z

[16] Gerede, D.M., et al. (2015) Case Report: A Giant Left Atrial Myxoma Neovascularized from the Right Coronary Artery. Case Reports in Cardiology, 2015, Article ID: 614830 .

[17] Marinissen, K.I., Essed, C., de Groot, C., et al. (1987) Growth Rate of Left Atrial Myxoma. Development of a Symptomatic Left Atrial Myxoma Less than Two Years after Coronary Artery Bypass Grafting. Chest, 92, 941-942. https://doi.org/10.1378/chest.92.5.941

[18] Stoddard, M.F., Liddell, N.E., Korfhage, L.A. and Kupersmith, J. (1992) The Transesophageal Echocardiographic Diagnosis of Left Atrial Myxoma Simulating a Left Atrial Thrombus in the Setting of Mitral Stenosis. Clinical Cardiology, 15, 379-382. https://doi.org/10.1002/clc.4960150515

[19] Janas, R., et al. (2006) Should We Perform Preoperative Coronary Angiography in All Cases of Atrial Myxomas? Catheterization and Cardiovascular Interventions, 67, 379-383. https://doi.org/10.1002/ccd.20643

Submit or recommend next manuscript to SCIRP and we will provide best service for you:

Accepting pre-submission inquiries through Email, Facebook, LinkedIn, Twitter, etc. A wide selection of journals (inclusive of 9 subjects, more than 200 journals)

Providing 24-hour high-quality service

User-friendly online submission system

Fair and swift peer-review system

Efficient typesetting and proofreading procedure

Display of the result of downloads and visits, as well as the number of cited articles

Maximum dissemination of your research work

Submit your manuscript at: http://papersubmission.scirp.org/

Or contact ijcm@scirp.org 